\title{
TOPOGRAPHY OF DIAPHYSEAL FORAMINA IN BONES OF UPPER EXTREMITY AND ITS SURGICAL IMPLICATIONS
}

\author{
Saroj Kumar ${ }^{1}$, Venkatesh Kamath *2, Muhammed Asif ${ }^{3}$, Shivarama Bhat ${ }^{4}$, Md. \\ Tabrej Alam ${ }^{5}$.
}

${ }^{1}$ Associate Professor, Department of Anatomy, Hind Institute of Medical Sciences, Sitapur, Uttar Pradesh, India.

${ }^{* 2}$ Associate Professor, Department of Anatomy, G.S.L. Medical College, Rajahmundry, Andhra Pradesh, India.

${ }^{3}$ Lecturer, Department of Anatomy, Yenepoya Medical College, Mangalore, Karnataka, India.

${ }^{4}$ Professor, Department of Anatomy, Yenepoya Medical College, Mangalore, Karnataka, India.

${ }^{5}$ Assistant Professor, Department of Anatomy, Hind Institute of Medical Sciences, Sitapur, Uttar Pradesh, India.

\section{ABSTRACT}

Background and aims: The recent developments in the field of bone grafting surgeries make it imperative for a surgeon to understand precisely the topography of the nutrient foramina to ensure procedural success without vascular compromise.

Materials and Methods: The study involved 205 bones, which included 70 humerus, 71 radii and 64 ulnae. The position and number of the primary diaphyseal nutrient foramina in each of the bones was studied.

Results: It was observed that all the bones have a single primary nutrient foramen. The mean foraminal index was 55.41 for humerus, 34.84 for radius and 35.86 for ulna. In the humerus, the primary diaphyseal foramen is usually observed in the middle third of the bone and in the radius and ulna it is observed predominantly in the junction between the upper and middle third. In the humerus the foramen is predominantly seen on the anteromedial surface $(95.71 \%)$. In the radius and ulna, the primary diaphyseal foramen was predominantly seen on the anterior surface with a $91.54 \%$ incidence in radius and $100 \%$ incidence in the ulna.

Conclusion: An orthopedic surgeon performing a bone graft or a joint replacement or internal fixation involving precise positioning of plate or a vascularized bone microsurgery must be familiar with the precise location of the nutrient foramen for preserving the vasculature of bone and ensuring good postoperative prognosis.

KEY WORDS: bone grafting; foraminal index; nutrient artery; nutrient foramen; surgical implications.

Address for Correspondence: Dr. Venkatesh Kamath, Associate Professor, Department of Anatomy, G.S.L. Medical College, NH-16, Lakshmipuram, Rajahmundry, Andhra Pradesh, India 533296. phone no: 9651710187 E-Mail: drvenkateshkamath@gmail.com

\section{Access this Article online}

\section{Quick Response code}

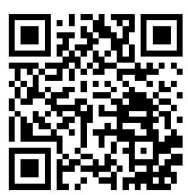

DOI: $10.16965 /$ ijar.2017.462

Web site: International Journal of Anatomy and Research ISSN 2321-4287

www.ijmhr.org/ijar.htm

Received: 26 Sep 2017

Peer Review: 26 Sep 2017

Revised: None
Accepted: 08 Nov 2017

Published (O): 01 Dec 2017

Published (P): 01 Dec 2017

\section{INTRODUCTION}

The artery that supplies nutrition to the bone is termed as the nutrient artery and the foramen through which it enters the medullary cavity is termed as the diaphyseal nutrient foramen [1]. The diaphyseal nutrient arteries constitute the predominant mode of nutrition to the bone during development in embryonic stages and in 
postnatal growing period especially during early ossification [2]. The nutrient artery is directed away from the growing end of the bone and it is often quoted as seeking the elbow and fleeing from the knee [3]. The knowledge of the position and number of nutrient foramina is essential for success of bone transplantation procedures [4]. The success of a bone graft depends upon the acceptance of the graft by the recipient and this demands adequate nutrition at the site of the procedure and a good vascular bed which must be provided by the surgeon. Hence it is mandatory for a surgeon to precisely understand the topography of the nutrient foramina at the operative site thus preserving the vascularization required and enabling good postoperative prognosis [5] Similarly adequate vascularization of bone is vital at fracture site for fracture healing [6] and at operative site for regeneration of osteocytes and osteoblasts following tumor resection and trauma [7].

The knowledge of topography of nutrient foramina constitutes the basis on which the orthopedic surgeons formulate newer and more successful transplantation and resection techniques [8]. An intraoperative damage to the nutrient artery can be avoided by precisely studying the topography of the operating site prior to the procedure [9]. The relative position of the nutrient foramen to the site of trauma determines the prognosis following the injury. It is observed that in the upper extremities the nutrient foramina are closer to the elbow than the shoulder or the wrist [10].

Forriol Campos et al. have also made a similar observation in their study which states that the diaphyseal nutrient foramina are observed between 50 to $65 \%$ of humeral length and 25 to $50 \%$ of radial and ulnar length [11]. This implies that fractures around the elbow heal well provided the blood supply is uncompromised by the trauma. The upper limb bones are prone to fractures such as fracture of surgical neck of humerus, supracondylar fracture of humerus and Colles and Smith fracture of radius and these cases are routinely encountered in clinical practice. It is therefore essential to study the topography of the nutrient foramen of these bones and the authors hope that this study is useful to orthopedic surgeons.

\section{MATERIALS AND METHODS}

The study was conducted in the Department of Anatomy at Hind Institute of Medical Sciences, Sitapur, Uttar Pradesh, India. The study involved 70 humerus, 71 radii and 64 ulnae. Morphologically normal bones were selected for the study. Those with any pathological deformity were excluded. Sex determination and age determination was not done. The study involved only the primary diaphyseal nutrient foramina. Secondary foramina smaller than a size 24 hypodermic needle were excluded [12]. Primary nutrient foramina were identified by the presence of a groove leading to the foramina and a raised edge at their commencement. $A$ magnifying lens was used to locate the foramen. The surface of the bone on which the foramen was located was noted. The foraminal index (FI) was calculated using the Hughes formula [13] which considers the distance of the foramen from the proximal end of the bone (PF) and the total length of the bone (TL).

$\mathrm{FI}=\mathrm{PF} / \mathrm{TL} \times 100$

Based on the foraminal index the position of the foramen was described

A. Index less than 33.33 indicates the foramen is located in the proximal third.

B. Index between 33.33 and 66.66 indicates the foramen is located in the middle third.

C. Index more than 66.66 indicates the foramen is located in the distal third [14].

Total length (TL) of the bone is the length from point $T$, the highest point on the head of the humerus to point $L$ the lowest point on the medial edge of trochlea. PF depicts the length from the proximal end of the bone to the nutrient foramen. $\mathrm{FI}=\mathrm{PF} / \mathrm{TL} \times 100$

Fig. 1: Depicts the technique of measurement of foraminal index in humerus.

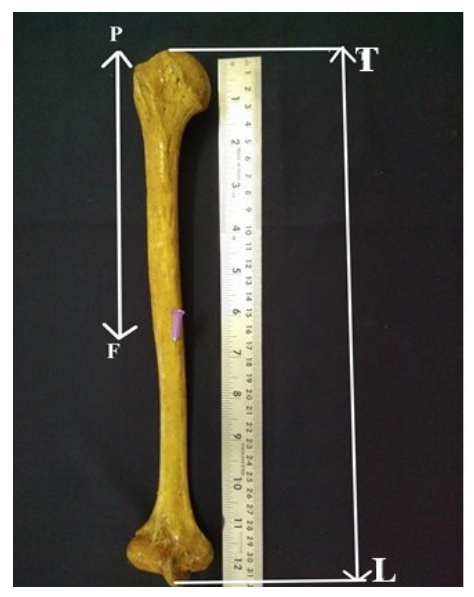


Length from point $T$, the highest point on the head of the radius to point $L$ the lowest point on tip of the styloid process of radius is TL. PF depicts the length from the proximal end of the bone to the nutrient foramen.

Fig. 2: Depicts the technique of measurement of foraminal index in radius.

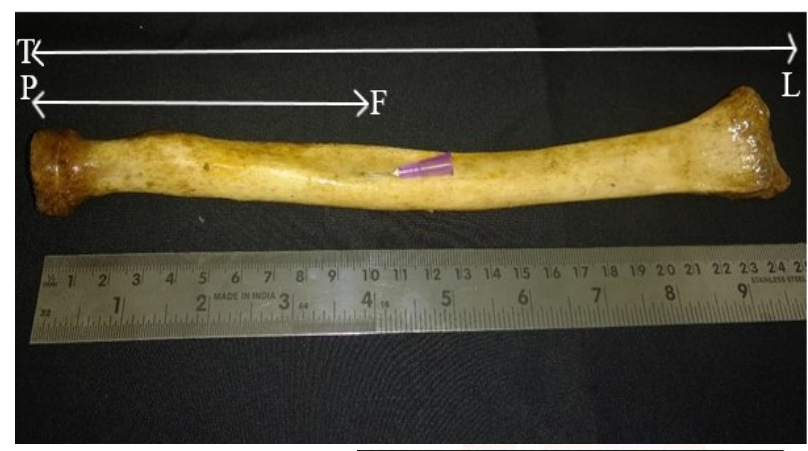

Fig.3: Depicts the technique of measurement of foraminal index in ulna.

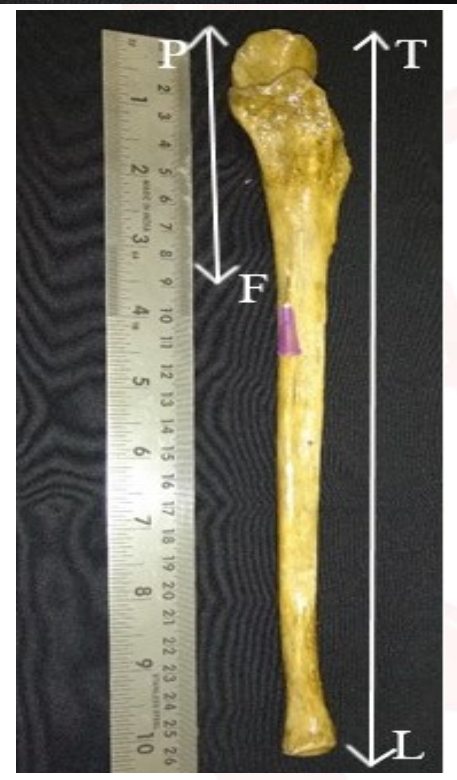

Length from point $T$, the highest point on the olecranon process of ulna to point $L$ the lowest point on tip of the styloid process of ulna is TL. PF depicts the length from the proximal end of the bone to the nutrient foramen.

\section{RESULTS}

Table 1: Depicts the topography of primary diaphyseal foramina in the humerus.

\begin{tabular}{|c|c|c|c|c|c|c|}
\hline \multirow{2}{*}{ Surface } & \multicolumn{2}{|c|}{ Number of foramina } & \multicolumn{3}{c|}{ Percentage of foramina (\%) } \\
\cline { 2 - 7 } & Right & Left & Total & Right & Left & Total \\
\cline { 2 - 7 } & $\mathrm{n}=34$ & $\mathrm{n}=36$ & $\mathrm{n}=70$ & $\%$ & $\%$ & $\%$ \\
\hline Antero-medial & 32 & 35 & 67 & 94.12 & 97.22 & 95.71 \\
\hline Antero-lateral & 0 & 0 & 0 & 0 & 0 & 0 \\
\hline Posterior & 2 & 1 & 3 & 5.88 & 2.77 & 4.28 \\
\hline
\end{tabular}

As observed in table $1,95.71 \%$ of primary diaphyseal foramina are observed in the anteromedial surface of the humerus and $4.28 \%$ of foramina are observed on the posterior surface of the bone. No foramina were observed on the antero-lateral surface. This implies that great caution must be excised while operating on the antero-medial surface of humerus to avoid damage to vascularity.

Table 2: Depicts the topography of primary diaphyseal foramina in the radius.

\begin{tabular}{|c|c|c|c|c|c|c|}
\hline \multirow{3}{*}{ Surface } & \multicolumn{3}{|c|}{ Number of foramina } & \multicolumn{3}{c|}{ Percentage of foramina (\%) } \\
\cline { 2 - 7 } & Right & Left & Total & Right & Left & Total \\
\cline { 2 - 7 } & $\mathrm{n}=34$ & $\mathrm{n}=36$ & $\mathrm{n}=70$ & $\%$ & $\%$ & $\%$ \\
\hline Anterior & 30 & 35 & 65 & 93.75 & 89.74 & 91.54 \\
\hline Posterior & 2 & 4 & 6 & 6.25 & 10.25 & 8.45 \\
\hline Lateral & 0 & 0 & 0 & 0 & 0 & 0 \\
\hline
\end{tabular}

It is evident from table 2, that the incidence of primary diaphyseal foramina on the anterior surface of the radius is $91.54 \%$ and $8.45 \%$ on the posterior surface. No foramina were observed on the lateral surface of the bone. This implies that great caution must be excised while operating on the anterior surface of radius to avoid damage to vascularity.

Table 3: Depicts the topography of primary diaphyseal foramina in the ulna.

\begin{tabular}{|c|c|c|c|c|c|c|}
\hline \multirow{3}{*}{ Surface } & \multicolumn{3}{|c|}{ Number of foramina } & \multicolumn{3}{c|}{ Percentage of foramina (\%) } \\
\cline { 2 - 7 } & Right & Left & Total & Right & Left & Total \\
\cline { 2 - 7 } & $\mathrm{n}=34$ & $\mathrm{n}=36$ & $\mathrm{n}=70$ & $\%$ & $\%$ & $\%$ \\
\hline Anterior & 30 & 34 & 64 & 100 & 100 & 100 \\
\hline Posterior & 0 & 0 & 0 & 0 & 0 & 0 \\
\hline Medial & 0 & 0 & 0 & 0 & 0 & 0 \\
\hline
\end{tabular}

It is evident from table 3 (above) that 100 percent of primary diaphyseal nutrient foramina are observed on the anterior surface in the ulna. This implies that an orthopedic surgeon must excise great caution while operating on the anterior surface of ulna to avoid damage to its vascularity.

Table 4: Depicts the mean foraminal index in humerus, radius and ulna.

\begin{tabular}{|c|c|c|c|}
\hline \multirow{2}{*}{ Bone } & \multicolumn{3}{|c|}{ Mean Foraminal Index } \\
\cline { 2 - 4 } & Right & Left & Total \\
\hline Humerus & 54.56 & 56.26 & 55.41 \\
\hline Radius & 34.68 & 35.01 & 34.84 \\
\hline Ulna & 35.82 & 35.9 & 35.86 \\
\hline
\end{tabular}

The mean foraminal index of all the bones is shown in table 4 . The mean foraminal index is 55.41 for humerus, 34.84 for radius and 35.86 for ulna. This implies that in the humerus, the primary diaphyseal foramina is predominantly located in the middle third and in the radius and 
the ulna in the junction between the upper and middle third.

To summarize the results, an orthopedic surgeon must excise great caution while operating on the anteromedial surface in the middle third of humerus and on the anterior surface of the radius and the ulna in the junction between their upper and middle third to avoid damage to the vasculature as most of the primary diaphyseal foramina exist in this region.

\section{DISCUSSION}

It is observed that nutrient foramina are usually found in the flexor aspect of the long bones in humans. The vessels that invade the bone during ossification often give rise to the regional nutrient artery [6]. The nutrient foramina usually have a specific location on the bone [15]. Variations in the location of the foramina are more common in the weight bearing bones like femur and much less common in the humerus, radius and ulna [13]. Studies have shown that there is no relationship between the length of the bone and the number of nutrient foramina. No relationship is observed either between the number of ossification centres and the number of foramina. Example, femur with one primary ossification centre has two foramina and clavicle with two centres often has a single foramen [3]. The brachial artery or the profunda brachi artery gives rise to the nutrient artery in the humerus [16]. In the radius the nutrient artery arises from the anterior interosseous artery and in the ulna from the ulnar or anterior interosseous artery [17].

Several authors have studied the nutrient foramina of long bones and this knowledge has profound surgical implications in orthopaedic procedures.

Humerus: In this study, $95.71 \%$ of primary diaphyseal foramina were observed in the antero-medial surface of the humerus and $4.28 \%$ on the posterior surface. Similar observation of foraminal predominance in antero-medial surface was made by other authors, such as Forriol Campos et al. [11], Kizilkanat et al. [9] and Pereira, G. A. M. et al. [10] Murlimanju et al. observed $54 \%$ of foramina in anteromedial surface and $31 \%$ on medial border [18].

Mysorekar reported $40 \%$ on anteromedial sur- face, $40 \%$ on medial border and $19 \%$ in the spiral groove [16]. The mean foraminal index in our study is 55.41 . This observation is close to that of Pereira, G. A. M. et al. [10] who studied 174 bones and observed a mean foraminal index of 55.2. Among other studies, it was observed that the foramina are predominantly located between $43-66 \%$ of humerus length by Murlimanju et al. [18], 15-69 \% of humerus length by Kizilkanat et al. [9] and 50 to $65 \%$ of humerus length by Forriol Campos et al. [11] Mysorekar noted that $70 \%$ of the foramina were observed in four sixth portion of the bone and $25.5 \%$ on three sixth portion of the bone [16]. Only a single nutrient foramen was observed in all the bones in this study while authors like Mysorekar have reported double foramina in humerus [16].

Radius: In this study, $91.54 \%$ foramina were observed on the anterior surface of the radius and $8.45 \%$ on the posterior surface. Mysorekar observed that $75 \%$ of foramina were on the anterior surface of the bone, $9 \%$ on the posterior surface and rest on the interosseous border [16]. Among other studies, the nutrient foramina were observed on the anterior surface of radius in $72.2 \%$ cases by Murlimanju et al. [18], 73.2\% cases by Pereira, G. A. M. et al. [10] and in $100 \%$ cases by Forriol Campos et al. [11]. The mean foraminal index in our study is 34.84 . Among other studies, it was observed that the foramina are predominantly located between $26-46 \%$ of radius length by Murlimanju et al. [18], 22-46\% of radius length by Kizilkanat et al. [9] and 25 to $50 \%$ radius length by Forriol Campos et al. [11]. Mysorekar observed that $62 \%$ of foramina were in the middle third and $36 \%$ in the upper third and the rest in the junction between the two [16].

Ulna: In the present study 100 percent of primary diaphyseal nutrient foramina are observed on the anterior surface in the ulna. Among other authors, the foramina were predominantly observed in the anterior surface in $82.2 \%$ cases by Pereira, G. A. M. et al. [10] and Forriol Campos et al. [11], in $86.7 \%$ cases by Murlimanju et al. [18] and in 73\% cases by Mysorekar [16]. The mean foraminal index in our study is $\mathbf{3 5 . 8 6}$ for ulna. Among other studies it was observed that the foramina are predominantly located between 
$25-58 \%$ of ulnar length by Murlimanju et al. [18], 27-54 \% of ulnar length by Kizilkanat et al. [9] and 25 to $50 \%$ ulnar length by Forriol Campos et al. [11].

\section{CONCLUSION}

Studying the topography of nutrient foramina helps in successfully planning bone surgeries. If we know the precise location of the nutrient foramen we can excise great caution while operating at those sites using plate fixation and implantations. In the humerus the foramen is predominantly observed in the antero-medial surface in the middle third and in the radius and ulna in the anterior surface in the junction between the upper and middle third. One of the basic prerequisites for good healing following a fracture is good vascularity at the fracture site. Hence it is very much essential to preserve the nutrient artery and we believe that this study will contribute to better understanding of foraminal topography. An orthopedic surgeon performing a bone graft or a joint replacement or internal fixation involving precise positioning of plate or a vascularized bone microsurgery must be familiar with the precise location of the nutrient foramen for preserving the vasculature of bone and ensuring good postoperative prognosis.

\section{Conflicts of Interests: None}

\section{REFERENCES}

[1]. Lewis OJ. The blood supply of developing long bones with special reference to the metaphyses. J Bone Joint Surg Br. 1956;38-B:928-933.

[2]. Sendemir E, Cimen A. Nutrient foramina in the shafts of lower limb long bones: situation and number. Surg Radiol Anat. 1991;13:105-108.

[3]. Patake SM, Mysorekar VR. Diaphysial nutrient foramina in human metacarpals and metatarsals. J Anat. 1977;124:299-304.

[4]. Taylor GI. Fibular transplantation. In: Serafin D, Bunke HJ (eds), Microsurgical composite tissue transplantation, C.V.Mosby Co., St. Louis, 1979;418423.
[5]. Wavreille G, Dos Remédios C, Chantelot C, Limousin $\mathrm{M}$, Fontaine $\mathrm{C}$. Anatomic bases of vascularized elbow joint harvesting to achieve vascularized allograft. Surg Radiol Anat. 2006;8:498-510.

[6]. Longia GS, Ajmani ML, Saxena SK, Thomas RJ. Study of diaphyseal nutrient foramina in human long bones. Acta Anat. 1980;107:399-406.

[7]. Gümüsburun E, Yücel F, Ozkan Y, Akgün Z. A study of the nutrient foramina of lower limb long bones. Surg Radiol Anat. 1994;16:409-412.

[8]. Kirschner MH, Menck J, Hennerbichler A, Gaber O, Hofmann GO. Importance of arterial blood supply to the femur and tibia for transplantation of vascularized femoral diaphyses and knee joints. World J Surg 1998;22:845-852.

[9]. Kizilkanat E, Boyan N, Ozsahin ET, Soames R, Oguz $O$. Location, number and clinical significance of nutrient foramina in human long bones. Ann Anat. 2007;189:87-95.

[10]. Pereira GAM, Lopes PTC, Santos AMPV, Silveira FHS. Nutrient foramina in the upper and lower limb long bones: Morphometric study in bones of Southern Brazilian adults. Int. J. Morphol. 2011;29:514-520.

[11]. Forriol Campos F, Gomez Pellico L, Gianonatti Alias M, Fernandez-Valencia R. A study of the nutrient foramina in human long bones, Surg Radiol Anat. 1987;9:251-255.

[12]. Lee JH, Ehara S, Tamakawa Y, Horiguchi M. Nutrient canal of the fibula. Skeletal Radiol. 2000;29:22-6.

[13]. Hughes $H$. The factors determining the direction of the canal for the nutrient artery in the long bones of mammals and birds. Acta Anat (Basel). 1952;15:261-280.

[14]. Ukoha UU, Umeasalugo KE, Nzeako HC, Ezejindu DN, Ejimofor OC, Obazie IF. A study of nutrient foramina in long bones of Nigerians. National journal of medical research. 2013;3:304-308.

[15]. Payton CG. The position of the nutrient foramen and direction of the nutrient canal in the long bones of the madder-fed pig, J Anat. 1934;68(Pt 4):500-510.

[16]. Mysorekar VR, Diaphysial nutrient foramina in human long bones, J Anat, 1967;101(Pt 4):813-822.

[17]. Giebel GD, Meyer Ch, Koebke J, Giebel G, Arterial supply of forearm bones and its importance for the operative treatment of fractures, Surg Radiol Anat. 1997;19(3):149-153.

[18]. Murlimanju BV, Prashanth KU, Prabhu LV, Kumar CG, Pai MM, Dhananjaya KVN. Morphological and topographical anatomy of nutrient foramina in the lower limb long bones and its clinical importance. AMJ. 2011;4:530-537.

How to cite this article:

Saroj Kumar, Venkatesh Kamath, Muhammed Asif, Shivarama Bhat, Md. Tabrej Alam. TOPOGRAPHY OF DIAPHYSEAL FORAMINA IN BONES OF UPPER EXTREMITY AND ITS SURGICAL IMPLICATIONS. Int J Anat Res 2017;5(4.3):4746-4750. DOI: 10.16965/ijar.2017.462 